\title{
Effects of intermittent hypoxia on A-/E-FABP expression in human aortic endothelial cells
}

\author{
Qian Han ${ }^{\text {a }}$, Sze C. Yeung ${ }^{\text {a }}$, Mary S.M. Ip ${ }^{\text {a,c }}$, Judith C.W. Mak ${ }^{\text {a,b,c,* }}$ \\ a Department of Medicine, Li Ka Shing Faculty of Medicine, The University of Hong Kong, Hong Kong, China \\ b Department of Pharmacology \&' Pharmacy, Li Ka Shing Faculty of Medicine, The University of Hong Kong, Hong Kong, China \\ ${ }^{c}$ Research Centre of Heart, Brain, Hormone and Healthy Aging, The University of Hong Kong, Hong Kong, China
}

\section{A R T I C L E I N F O}

\section{Article history:}

Received 23 February 2010

Accepted 8 April 2010

Available online $\mathrm{xxxx}$

\section{Keywords:}

Aortic endothelial cells

Fatty acid-binding protein

Intermittent hypoxia

Obstructive sleep apnea

Obstructive sleep apnea (OSA) is a prevalent disorder affecting at least $9 \%-15 \%$ middle-aged adults, which is characterized by repetitive cycles of hypoxia followed by reoxygenation termed intermittent hypoxia (IH) [1]. Recently, there is growing epidemiologic and clinical data showing excess of cardiovascular morbidity and mortality in OSA subjects [2]. However, it remains unknown whether OSA contributes directly to atherogenesis or merely serves as a modifier of other effects.

Fatty acid-binding proteins (FABPs) are a group of molecules facilitating lipid transportation within cells. To date, at least nine subtypes have been described [3], each named after the first tissue isolation or identification: L (liver), I (intestinal), H (muscle and heart), A (adipocyte), E (epidermal), I (ileal), B (brain), M (myelin) and T (testis). Among them, A- and E-FABP have been suggested to play a role in atherosclerosis based on knock-out mice models [4] and clinical studies [5,6]. Subjects with severe OSA were also found to have elevated serum A-FABP levels [7], suggesting a mediating role between OSA and atherosclerosis.

Systemic inflammation has been suggested as an intermediary mechanistic pathway for OSA-related cardiometabolic sequelae [8]. Among inflammatory cytokines, TNF- $\alpha$ is a potent pro-atherogenic factor to be increased in the serum of OSA subjects compared to obese controls [9]. Thus the aim of the present study was to investigate the effects of IH or/and TNF- $\alpha$ on A-/E-FABP expressions in endothelial cells.

Human abdominal aortic endothelial cells (HAAE) were obtained from ATCC and passages 3-9 were used for the experiment. Confluent

\footnotetext{
* Corresponding author. Room 804, Administration Block, Queen Mary Hospital, Pokfulam Road, Hong Kong, China. Tel.: + 852 28555886; fax: + 85228186474.

E-mail address: judithmak@hkucc.hku.hk (J.C.W. Mak).
}

cells seeded in 6-well plates were starved for 1 day in 1\% FBS medium before exposure to atmospheric air or intermittent hypoxia (IH), in the absence or presence of $10 \mathrm{ng} / \mathrm{ml} \mathrm{TNF}-\alpha$ (Biosource). The IH protocol consisted of 64 cycles of 10 -min hypoxia period $\left(5 \% \mathrm{O}_{2}\right.$ and $\left.5 \% \mathrm{CO}_{2}\right)$ followed by 5 -min reoxygenation $\left(21 \% \mathrm{O}_{2}\right.$ and $\left.5 \% \mathrm{CO}_{2}\right)$, using the BioSpherix OxyCycler C42 system (BioSpherix, Redfield, NY, USA).

3-(4,5-Dimethylthiazol-2-yl)-2,5-diphenyltetrazolium bromide (MTT) assay was used to assess cell viability. Cells exposed to atmospheric air alone were considered to be $100 \%$ viable.

Total RNA from cells was extracted using Trizol reagent (Ambion Inc.) according to the manufacturer's protocol. First-strand cDNA was synthesized from $1 \mu \mathrm{g}$ of total RNA using an oligo (dT) primer and MMLV RT kit (Invitrogen), and then amplified in a final volume of $20 \mu \mathrm{l}$ using FastStart Taq DNA polymerase (Roche). The amplified products were separated on $1.5 \%$ agarose gels and visualized by ethidium bromide staining. The expression levels of A-/E-FABP mRNAs was quantified after normalization with guanine nucleotide binding protein), beta polypeptide 2-like 1 (GNB2L1) mRNA.

Cells were lysed in CelLytic M mammalian cell lysis/extraction reagent (Sigma) supplemented with $1 / 100(\mathrm{v} / \mathrm{v})$ protease inhibitor cocktail (Calbiochem). The cell lysate was centrifuged at $14,000 \mathrm{~g}$ for $15 \mathrm{~min}$ at $4{ }^{\circ} \mathrm{C}$ and protein concentration in the supernatant was measured using BioRad protein assay. Total cell lysate $(40 \mu \mathrm{g})$ was separated by SDS-polyacrylamide gel, and then transferred to a nitrocellulose membrane (Amersham Biosciences). After blocking in phosphate buffered saline containing $0.1 \%(\mathrm{v} / \mathrm{v})$ Tween and $5 \%(\mathrm{w} / \mathrm{v})$ dried milk, the protein expression level was examined using anti-A-FABP goat polyclonal (1:200; Santa Cruz Bioechnology) and anti-E-FABP rabbit polyclonal (1:2000; Biovender Laboratory Medicine Inc.) antibodies. $\beta$-actin was used for the normalization of A-/E-FABP expression. Membranes were then incubated with horseradish peroxidase-conjugated anti-mouse, anti-rabbit or anti-goat IgG (Dako) and analyzed by chemiluminescence (Amersham). Densitometric analysis of bands was performed with GeneTools (Syngene, Frederick, MD, USA) to determine the respective protein expression levels.

Data were expressed as means \pm SEM from at least 4 independent experiments. Data were analyzed by Student's $t$ test using GraphPad Prism 3.0 (GraphPad Software Inc, San Diego, CA, USA). A p-value $<0.05$ was considered statistically significant.

Our results for cell viability indicated that there was no difference between the control group and other treatment groups, indicating that neither IH nor TNF- $\alpha$ affected cell proliferation in our experimental model. IH alone significantly upregulated A-/E-FABP mRNA and protein expression levels. TNF- $\alpha$ also induced a trend of increase, while a 
A
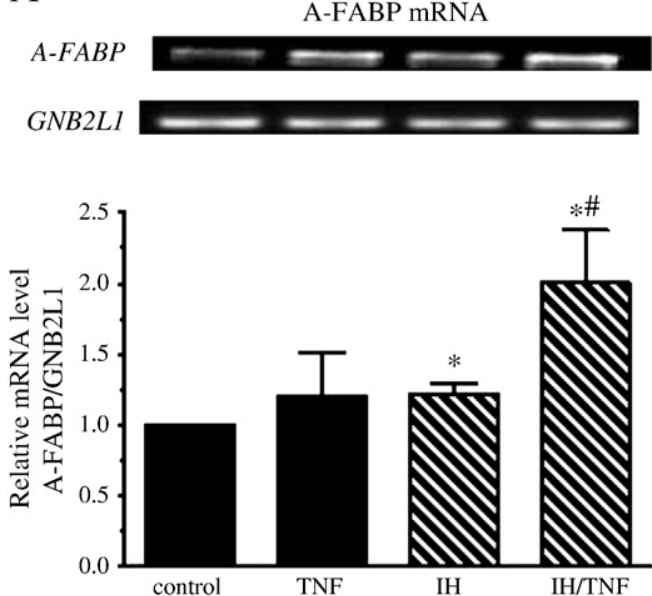

C
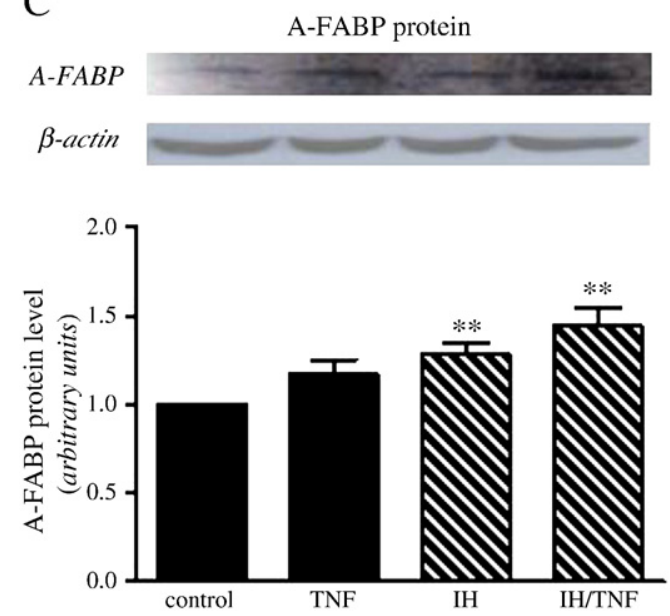

B

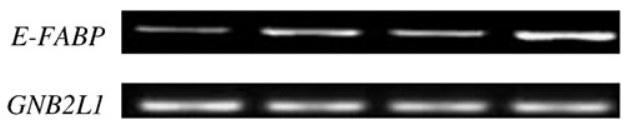

GNB2L

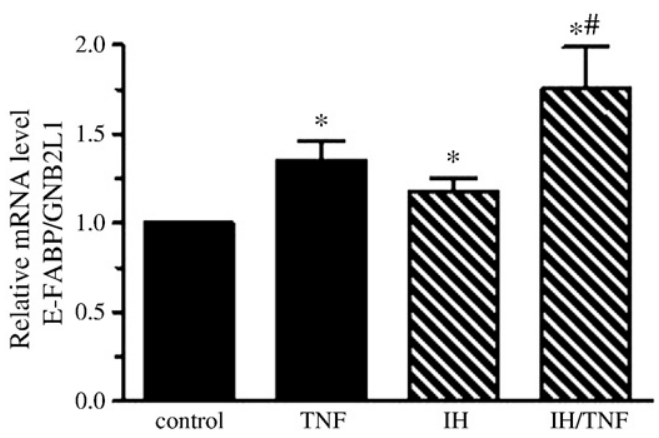

D
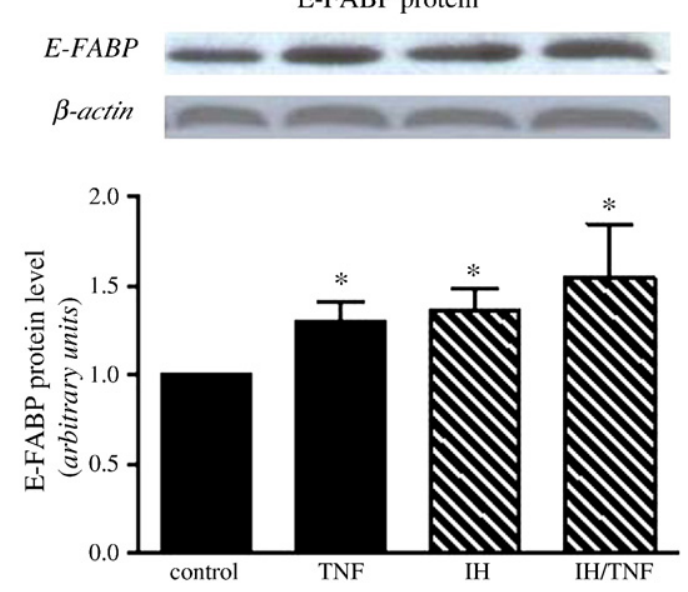

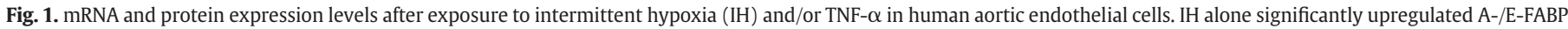

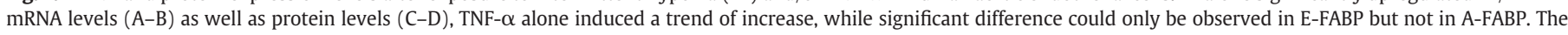

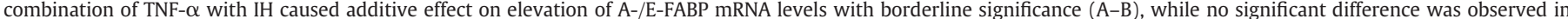

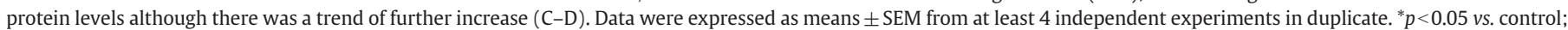
${ }^{* *} p<0.01$ vs. control; ${ }^{\#} 0.05<p<0.06$ vs. IH.

significant difference could only be observed in E-FABP but not A-FABP. While the combination of TNF- $\alpha$ and IH caused a marginally higher elevation of A-/E-FABP mRNA levels compared to IH alone $(p=0.056$ for A-FABP and $p=0.055$ for E-FABP respectively), no significances were achieved at their protein levels (Fig. 1A-D).

There is accumulating evidence that OSA is associated with cardiovascular risks, especially atherosclerosis. However, due to high comorbid prevalence of other atherogenic risk factors, such as obesity, aging, hypertension, diabetes, and hyperlipidemia, it remains unclear whether OSA contributes directly to atherogenesis.

Atherosclerosis has been suggested to be an immunoimflammatory disease involving multiple pathways and a plethora of cell types. Endothelial cells and macrophages have been regarded as two active partners involved in the initiation and progression of atherosclerosis. Recently, two isoforms of FABP family, A- and E-FABP, have been detected to play a significant role in atherosclerosis, thereby giving rise to great interests and further exploration. Both circulating A- and EFABP levels have been found to be independently associated with carotid atherosclerosis in clinical studies [5,6], and combined A- and EFABP deficiency could provide synergistic protective effect on atherosclerosis in apoE $\mathrm{E}^{-1-}$ mice [4]. To date, the atheroprotective effect of AFABP has been demonstrated to be predominantly related to its actions in macrophage [10]. To our knowledge, this is the first study to detect the co-expression of A- and E-FABP in cultured human aortic endothelial cells, which is the critical cellular component in the development of atherosclerosis. We also found that IH could elevate A- and E-FABP expression levels, and the presence of TNF- $\alpha$ might partially potentiate such effect. These data, together with previous clinical results showing elevated serum A-FABP levels in otherwise healthy men with severe OSA [7], imply that FABP may serve as a linkage between OSA and atherosclerosis. Further studies will be necessary to address the initial signaling events which occur in response to $\mathrm{IH}$.

\section{Acknowledgements}

This study was supported by the HKU-CRCG Seed Funding for Basic Research and Research Grant Council (RGC) Grant (7667/07M).

The authors of this manuscript have certified that they comply with the Principles of Ethical Publishing in the International Journal of Cardiology [11].

\section{References}

[1] Punjabi NM. The epidemiology of adult obstructive sleep apnea. Proc Am Thorac Soc 2008;5:136-43.

[2] Bradley TD, Floras JS. Obstructive sleep apnoea and its cardiovascular consequences. Lancet 2009;373:82-93.

[3] Furuhashi M, Hotamisligil GS. Fatty acid-binding proteins: role in metabolic diseases and potential as drug targets. Nat Rev Drug Discov 2008;7:489-503. 
[4] Boord JB, Maeda K, Makowski L, et al. Combined adipocyte-macrophage fatty acidbinding protein deficiency improves metabolism, atherosclerosis, and survival in apolipoprotein E-deficient mice. Circulation 2004;110:1492-8.

[5] Yeung DCY, Wang Y, Xu A, et al. Epidermal fatty-acid-binding protein: a new circulating biomarker associated with cardio-metabolic risk factors and carotid atherosclerosis. Eur Heart J 2008;29:2156-63.

[6] Yeung DCY, Xu A, Cheung CWS, et al. Serum adipocyte fatty acid-binding protein levels were independently associated with carotid atherosclerosis. Arterioscler Thromb Vasc Biol 2007;27:1796-802.

[7] Lam DC-LXuA, Lam KS-L, et al. Serum adipocyte-fatty acid binding protein level is elevated in severe OSA and correlates with insulin resistance. Eur Respir J 2009;33:346-51.
[8] Lam JC, Ip MS. Obstructive sleep apnea and the metabolic syndrome. Expert Rev Respir Med 2009;3:177-86.

[9] Ryan S, Taylor CT, McNicholas WT. Selective activation of inflammatory pathways by intermittent hypoxia in obstructive sleep apnea syndrome. Circulation 2005:112:2660-7.

[10] Boord JB, Maeda K, Makowski L, et al. Adipocyte fatty acid-binding protein, ap2, alters late atherosclerotic lesion formation in severe hypercholesterolemia. Arterioscler Thromb Vasc Biol 2002;22:1686-91.

[11] Coats AJ. Ethical authorship and publishing. Int J Cardiol 2009;131:149-50. 